I N S T I T U T O

$\mathrm{DE}$

M E D I C I N A

T R O P I C A L

DE

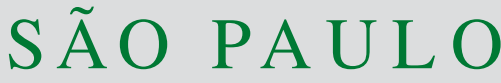

JOURNAL OF THE SÃO PAULO INSTITUTE OF TROPICAL MEDICINE

${ }^{1}$ Universidade Federal de São João del-Rei, Divinópolis, Minas Gerais, Brazil

${ }^{2}$ Universidade Federal de Minas Gerais, Belo Horizonte, Minas Gerais, Brazil

${ }^{3}$ Universidade Estadual de Montes Claros, Montes Claros, Minas Gerais, Brazil

${ }^{4}$ Universidade de São Paulo, Instituto de Medicina Tropical de São Paulo, São Paulo, São Paulo, Brazil

${ }^{5}$ Hospital Sírio-Libanês, Vital Strategies, São Paulo, São Paulo, Brazil

6Universidade Federal de Goiás, Instituto de Patologia Tropical e Saúde Pública, Programa de Pós-Graduação, Goiânia, Goiás, Brazil

${ }^{7}$ Universidade de São Paulo, Faculdade de Medicina, Instituto do Coração, Laboratório de Imunologia, São Paulo, São Paulo, Brazil

${ }^{8}$ Universidade de São Paulo, Faculdade de Medicina, Divisão de Imunologia Clínica e Alergia, São Paulo, São Paulo, Brazil

Correspondence to: Claudia Di Lorenzo Oliveira

Universidade Federal de São João del-Rei, Campus CCO, Rua Salinas, 931, Apto. 403 Bairro Sidil, CEP 35500-020, Divinópolis, MG, Brazil

E-mail: claudia.dlorenzo@gmail.com

Received: 28 June 2021

Accepted: 23 August 2021

\section{Cohort profile update: the main and new findings from the SaMi-Trop Chagas cohort}

\author{
Claudia Di Lorenzo Oliveira ${ }^{\circledR 1}$, Clareci Silva Cardoso ${ }^{\circledR 1}$, Nayara Ragi \\ Baldoni $^{\circledR 1}$, Larissa Natany ${ }^{\circledR 2}$, Ariela Mota Ferreira ${ }^{\circledR}$, Lea Campos de \\ Oliveira ${ }^{\circledR}$, Maria do Carmo Pereira Nunes ${ }^{\circledR}$, Nayara Dornela Quintino ${ }^{\left({ }^{1}\right.}$, \\ Ana Luiza Bierrenbach ${ }^{\sqrt{5} 6}$, Lewis F. Buss ${ }^{(14}$, Desiree Sant'Ana Haikal ${ }^{\circledR 3}$, \\ Edecio Cunha Neto ${ }^{1,8}$, Antonio Luiz Pinho Ribeiro ${ }^{(1)}$, Ester Cerdeira \\ Sabino 4
}

\section{ABSTRACT}

The SaMi-Trop project is a cohort study conducted in 21 municipalities of endemic areas of Chagas disease, including 1,959 patients with chronic Chagas cardiomyopathy. In this article we updated the results of the project, adding information from the second cohort visit. Trypanosoma cruzi-seropositive patients were enrolled from the primary care Telehealth service in Minas Gerais State, Brazil. The eligibility criterium for the second visit was the participation in the baseline evaluation. Of 1,959 participants at the baseline assessment, $1,585(79.9 \%)$ returned after two years for the second evaluation. The mortality rate was $6.7 \%$, but varied from $0.9 \%$ to $18.2 \%$ when it was stratified by certain clinical characteristics. A lower age-adjusted NT-Pro-BNP level (less than 300) and a prior benznidazole treatment were associated with lower mortality. There was an improvement in most quality of life domain scores. Participants have also reported fewer signs and symptoms and greater use of medication. The second follow-up visit will be complete in Oct 2021.

KEYWORDS: Chagas disease. Neglected diseases. Chagas cardiomyopathy. Cohort studies.

\section{INTRODUCTION}

Chagas disease $(\mathrm{ChD})$ is recognized by the World Health Organization as a neglected tropical disease, primarily affecting low-income populations in endemic areas. Millions of people are infected with Trypanosoma cruzi (T. cruzi), the causative agent, with most infected people living in Brazil and Argentina ${ }^{1}$. In addition, migration has resulted in large numbers of infected individuals in non-endemic countries such as Spain, the United States, Canada, Australia and $\mathrm{Japan}^{2,3}$. The control strategies of $T$.cruzi transmission implemented in the last 30 years have led to a reduction of approximately 10 million in the number of people living with $\mathrm{ChD}^{4}$. Nevertheless, around $13 \%$ of the population in Latin America is at risk of infection, where $\mathrm{ChD}$ accounts for more than 600,000 disability-adjusted life-years annually².

$\mathrm{ChD}$ is related to poverty, poor socioeconomic conditions, and to a lower quality of life ${ }^{5}$. In rural endemic areas, access to diagnosis and treatment is limited, resulting in a greater mortality ${ }^{6}$. Thus, the identification of patients with chronic Chagas cardiomyopathy (CCC) is important to guide public policies ${ }^{7}$ and special attention is required in this scenario. Many studies have pointed to the need of a permanent 
health care, as the morbidity and mortality are higher in patients with $\mathrm{ChD}$. These patients have worse prognosis and higher mortality ${ }^{8-10}$. A cohort study found that the mortality rate was 7.4 times higher in the group of patients with CCC compared with patients without cardiomyopathy ${ }^{11}$.

The SaMi-Trop (Sao Paulo-Minas Gerais Tropical Medicine Research Center) project aims to build understanding on the mechanisms of the cardiomiopathy development, to find biomarkers of the disease evolution, and to better understand the pathophysiology and clinical consequences of $\mathrm{ChD}^{12-15}$.

Clinical and laboratory markers predictive of severe and progressive $\mathrm{ChD}$ have been identified in the SaMi-Trop cohort, such as high age-adjusted brain-type natriuretic peptide (NT-Pro-BNP) levels, as well as symptoms of advanced heart failure ${ }^{12}$. The SaMi-Trop cohort is one of the largest multicenter studies of $\mathrm{ChD}$ conducted in endemic areas in the world. It represents a major opportunity for research focused on $\mathrm{ChD}$, generating knowledge that can be applied in the primary health care. To date, two visits were completed and the objective of this manuscript is to present the main results after six years of follow-up.

\section{MATERIALS AND METHODS}

The SaMi-Trop project is a prospective cohort study including $\mathrm{ChD}$ patients. It is organized and has been carried out by a network of collaborating scientists in Minas Gerais and Sao Paulo States, since 2013. The first study visit was in 2013-2014 (baseline) and the first follow-up (FU1) visit was performed in 2015-2016. The cohort was established to develop a prognostic algorithm, based on simple electrocardiogram (ECG) measurements in conjunction with clinical information and Brain Natriuretic Peptide (BNP) levels to predict the risk of disease progression and death in CCC patients, and also to be useful in the clinical management of such patients. In the second visit, some additional aims were included, namely: to test the clinical prediction rule developed during the first phase of the study, to expand the knowledge on the genetic basis of disease progression using a GWAS approach, to better understand how patients are being cared for by the health service, and to evaluate the level of health literacy and associated factors. This cohort study is conducted in 21 municipalities from Minas Gerais State, an endemic region for $\mathrm{ChD}$. It is integrated with the Telehealth Network in Minas Gerais. This State-wide Telehealth program has the technological infrastructure to facilitate the acquisition, cloud storage, and automatic recognition of ECG patterns and echocardiogram $(\mathrm{ECHO})$ images $^{16}$. The ECG reading center analyzes ECG using the Minnesota Code $^{17-19}$.
Potential participants were identified from the list of patients managed by the Telehealth Network, a program designed to support the primary care in Minas Gerais State ${ }^{11}$. The inclusion criteria in the baseline were patients aged 18 years or more, who self-reported $\mathrm{ChD}$ and abnormal alterations from the previous ECG recorded in a text report. All surviving baseline participants were invited to participate in the FU1 visit. Eligible patients were selected based on the ECG results performed in 2011-2012 by the Telehealth Network. The exclusion criteria included pregnancy or breastfeeding, and any life-threatening disease with an ominous prognosis that suggested a life expectancy of less than two years. More details regarding the eligible population, sample size, and other procedures can be found in the previously published paper ${ }^{12}$.

All participants evaluated in the baseline were contacted by telephone or letter and were invited to participate in the FU1. The FU1 protocol included a questionnaire, a blood collection to repeat the NT-proBNP measurement, an ECG and an ECHO. The ECHO was not performed in the baseline. Two new groups of questions were included in the questionnaire: a set of questions regarding the use of health services, and the SALPHA instrument to evaluate the health literacy ${ }^{20}$. The death certificates of participants who died before FU1 were obtained from the local health system. We repeated the serology test for participants with inconclusive or missing baseline $T$. cruzi serology results and 25 additional participants were included for serology testing in FU1. These participants were not included in the baseline because their blood samples were not available. The categorical variables were presented as percentages, and a test for equality matched pairs was performed to compare participants in both visits.

\section{RESULTS}

The SaMi-Trop cohort has been conducted in 21 municipalities in the North of Minas Gerais State, Brazil (Figure 1). In the baseline visit 1,959 T. cruzi-seropositive participants were enrolled, but we subsequently included 25 additional participants because their serological results became available. In this way, the final number of participants in the first follow-up was 1,585 (Figure 2). Table 1 shows the distribution of sociodemographic and clinical variables according to the final status on FU1. The overall mortality was $6.7 \%$, but the mortality rate varied from $0.9 \%$ to $18.2 \%$ when it was stratified according to clinical characteristics. The mortality was higher in older people (more than 50 years old), those with New York Heart Association (NYHA) functional classification of II or more, presence of Chagas cardiomyopathy and 
individuals with major ECG alterations. Regarding other clinical characteristics, those who died were associated with more coagulation problems in the baseline evaluation compared to those who survived (3.83\% vs $6.9 \%)$, more renal disease ( $7.6 \%$ vs $10.3 \%)$, infarction $(4.23 \%$ vs $15.2 \%)$, hypertension (64.4\% vs $73.8 \%)$, more use of amiodarone ( $21.6 \%$ vs $47.2 \%)$, and more pacemakers (5.3\% vs $14.6 \%$ ). Conversely, a lower NT-Pro-BNP level (less than 300) and prior benznidazole treatment were associated with lower mortality ${ }^{13,15}$. These results corroborate other studies ${ }^{21}$.

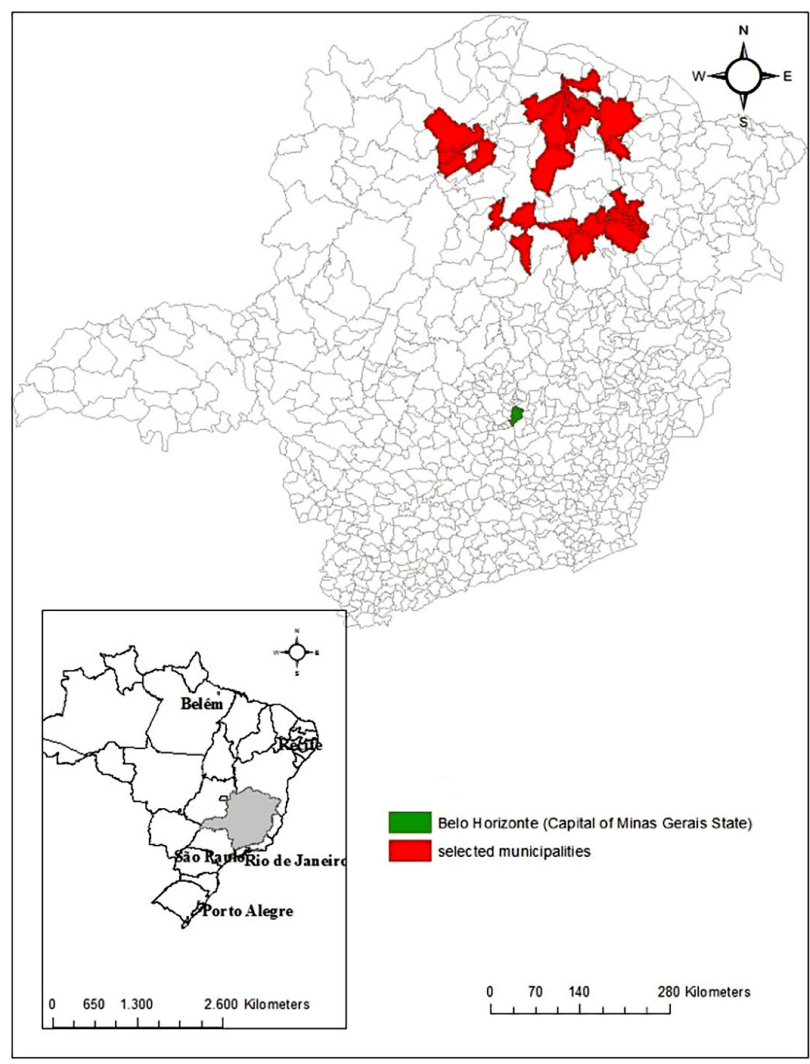

Figure 1 - Geographical location of the 21 municipalities included in the Sao Paulo-Minas Gerais Tropical Medicine Research Center (SaMi-Trop) project. Minas Gerais, Brazil.

Table 2 presents a comparison of sociodemographic variables at baseline and on FU1. Most variables remained stable between visits, except for the self-perception of health. Most of the participants were women (67.9\%), aged 50 years or more $(78.4 \%)$, that self-declared mixed skin color $(58.8 \%)$, and low education level $(79.4 \%)$. Clinical variables in both visits are shown in Table 3. According to the Short Assessment of Health Literacy for Portuguese-speaking Adults (SAHLPA), a health literacy tool $^{22}, 74 \%$ were classified as illiterate and $21.8 \%$ as having inadequate health literacy. There was an improvement in most quality of life domains. Better quality of life and clinical characteristics were associated with better medical

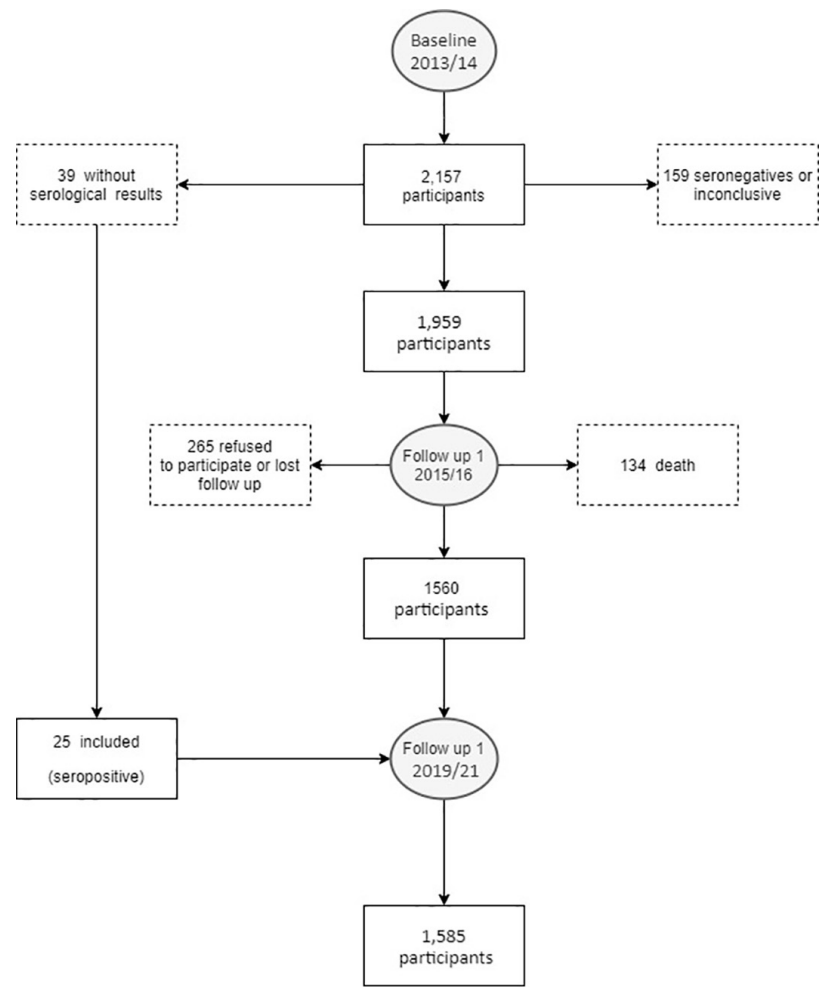

Figure 2 - Flowchart of the study participants. SaMi-Trop project.

care and treatment of $\mathrm{ChD}^{20}$. Thirteen percent of participants presented LV systolic dysfunction according to the ECHO findings.

Table 4 shows the prevalence of some comorbidities, behavioral characteristics, medication use as well as signs and symptoms at baseline and FU1 visits. The proportion of participants reporting high serum cholesterol levels fell by $11.4 \%$ ( $40.1 \%$ vs $28.7 \%$ ), but there was an increase of $29.2 \%$ in those reporting hypertension. Five new cases of leishmaniasis were registered among the participants. The proportion of subjects reporting current tobacco smoking decreased from $7.3 \%$ to $5.8 \%$. The proportion of participants with no regular medications reduced from $30.1 \%$ to $23.5 \%$, and those taking at least one medicine increased from $36.4 \%$ to $38.6 \%$. The proportion of participants classified as making use of polypharmacy (more than 5 medications) increased by $2.9 \%$ (6.0\% vs 8.9\%). The main medications accounting for this increase were angiotensin receptor blockers (ARBs) (28.4\% vs 33.3\%) and aspirin $(26.2 \%$ vs $29.5 \%)$. Medications that were prescribed less frequently at FU1 were angiotensin converting enzyme (ACE) inhibitors (28.6\%vs 23.3\%), amiodarone ( $22 \%$ vs $13.4 \%$ ), digoxin (7.2\%vs $5.1 \%$ ) and hydralazine (4.3\% vs $3.8 \%)$.

Participants reported less frequently "prolonged faintness or dizziness" (21.9\%vs 11.4\%), but had more "difficulty breathing when lying down" (39.1\%vs 42.5\%), 
Table 1 - Sociodemographic and clinical variables according to the status of the patients in the second follow-up visit (FU1): participated, died, or lost to follow-up.

\begin{tabular}{|c|c|c|c|c|}
\hline Variables & Valid $N^{*}$ & $\begin{array}{c}\text { Participated in FU1 } \\
\mathrm{N}(\%)\end{array}$ & $\begin{array}{l}\text { Lost to follow-up } \\
\mathrm{N}(\%)\end{array}$ & $\begin{array}{l}\text { Died } \\
\text { N/ (\%) }\end{array}$ \\
\hline Gender & 1,984 & $1,585(79.9)$ & $265(13.4)$ & $134(6.7)$ \\
\hline Female & 1,334 & $1,076 /(80.7)$ & $183 /(13.7)$ & $75 /(5.6)$ \\
\hline Male & 650 & $509 /(78.3)$ & $82 /(12.6)$ & $59 /(9.1)$ \\
\hline Age & 1,984 & 1,585 (79.9) & $265(13.4)$ & $134(6.7)$ \\
\hline$<50$ years & 489 & 408/(83.4) & $67 /(13.7)$ & $14 /(2.9)$ \\
\hline $50-74$ years & 1,227 & $1005 /(81.9)$ & $142 /(11.6)$ & $80 /(6.5)$ \\
\hline$>74$ years & 268 & $172 /(64.2)$ & $56 /(20.9)$ & $40 /(14.9)$ \\
\hline Household members & 1,984 & $1,585(79.9)$ & 265(13.4) & $134(6.7)$ \\
\hline $1-3$ & 1,128 & $885 /(78.5)$ & $161 /(14.3)$ & $82 /(7.3)$ \\
\hline $4-6$ & 717 & $588 /(82.0)$ & $84 /(11.7)$ & $45 /(6.3)$ \\
\hline $7-17$ & 139 & $112 /(80.6)$ & $20 /(14.4)$ & $7 /(5.0)$ \\
\hline Family monthly income ${ }^{\star \star}$ & 1,950 & $1,553(79.6)$ & 264(13.6) & $130(6.7)$ \\
\hline > US\$327 & 1,036 & $835 /(80.6)$ & $139 /(13.4)$ & $62 /(6.0)$ \\
\hline$\leq$ US $\$ 327$ & 914 & $718 /(78.6)$ & $126 /(13.8)$ & $70 /(7.6)$ \\
\hline Skin color & 1,974 & $1,578(79.9)$ & $265(13.4)$ & $131(6.6)$ \\
\hline Mixed & 1,155 & $928 /(80.3)$ & $141 /(12.2)$ & $86 /(7.4)$ \\
\hline White & 433 & $339 /(78.3)$ & $65 /(15.0)$ & $29 /(6.7)$ \\
\hline Black & 352 & $282 /(80.1)$ & $55 /(15.6)$ & $15 /(4.3)$ \\
\hline Others & 34 & 29/(85.3) & $4 /(11.8)$ & $1 /(2.9)$ \\
\hline Self-reported years of schooling & 1,950 & 1,555 (79.7) & $264(13.5)$ & $131(6.7)$ \\
\hline Illiterate & 670 & $508 /(75.8)$ & $92 /(13.7)$ & $70 /(10.4)$ \\
\hline 1 to 4 year & 862 & $721 /(83.6)$ & $94 /(10.9)$ & $47 /(5.4)$ \\
\hline 5 to 8 years & 320 & $242 /(75.6)$ & $66 /(20.6)$ & 12/(3.8) \\
\hline Other & 98 & $84 /(85.7)$ & $12 /(12.2)$ & $2(2.1)$ \\
\hline Marital status & 1,977 & $1,580(79.9)$ & $265(13.4)$ & $132(6.7)$ \\
\hline Married or living with partner & 1,251 & $1,022 /(81.7)$ & $154 /(12.3)$ & $75 /(6.0)$ \\
\hline Widower & 458 & $342 /(74.7)$ & $71 /(15.5)$ & $45 /(9.8)$ \\
\hline Single & 177 & $143 /(80.8)$ & $28 /(15.8)$ & 6/(3.4) \\
\hline Divorced & 91 & $73 /(80.2)$ & 12/(13.2) & $6 /(6.6)$ \\
\hline Previous use of benznidazole & 1,979 & 1,581 79.9) & $264(13.3)$ & $134(6.8)$ \\
\hline No & 1,335 & $1,055 /(79.0)$ & $180 /(13.5)$ & $100 /(7.5)$ \\
\hline Yes & 498 & 420/(84.3) & $64 /(12.8)$ & $14 /(2.8)$ \\
\hline Do not know & 146 & $106 /(72.6)$ & $20 /(13.7)$ & $20 /(13.7)$ \\
\hline NYHA functional classification & 1,966 & 1,570 (79.9) & $264(13.4)$ & $132(6.7)$ \\
\hline I & 1,065 & $895 /(84.0)$ & $126 /(11.8)$ & $44 /(4.1)$ \\
\hline II or more & 901 & $675 /(74.9)$ & $138 /(15.3)$ & $88 /(9.8)$ \\
\hline Chagas cardiomyopathy & 1,910 & 1,523 (79.7) & $259(13.6)$ & $128(6.7)$ \\
\hline Absent & 799 & 668/(83.6) & $114 /(14.3)$ & $17 /(2.3)$ \\
\hline Present & 1,111 & 855/(77.0) & $145 /(13.0)$ & $111 /(10.0)$ \\
\hline NT-proBNP level & 1,950 & 1,553 (79.6) & $263(13.5)$ & $134(6.7)$ \\
\hline$<300 \mathrm{pg} / \mathrm{mL}$ & 1,369 & $1,167 /(85.2)$ & $174 /(12.7)$ & $28 /(2.1)$ \\
\hline$\geq 300 \mathrm{pg} / \mathrm{mL}$ & 581 & $386 /(66.4)$ & $89 /(15.3)$ & 106 \\
\hline ECG result & 1,934 & $1,547(80.0)$ & $259(13.4)$ & $128(6.6)$ \\
\hline Minor & 476 & 392/(82.3) & $70 /(14.7)$ & $14 /(3.0)$ \\
\hline Normal & 332 & $285 /(85.8)$ & $44 /(13.2)$ & $3 /(0.9)$ \\
\hline Major & 1,126 & $870 /(77.3)$ & $145 /(12.9)$ & $111 /(9.9)$ \\
\hline
\end{tabular}

*25 participants were included because their serology at the baseline was lost, but they tested positive in the FU1 visit; ${ }^{* *}$ Dollar conversion is from July 2013 (US\$1.00 $=R \$ 2.23$ ). 
Table 2 - Sociodemographics, health satisfaction, and use of health service variables in the SAMI-TROP cohort at baseline and at the 2-years follow-up visit.

\begin{tabular}{|c|c|c|c|c|}
\hline \multirow{2}{*}{ Variables } & \multicolumn{2}{|c|}{ Baseline } & \multicolumn{2}{|c|}{ Follow-up 1} \\
\hline & Valid N & $\mathrm{N}(\%)$ & Valid N & $\mathrm{N}(\%)$ \\
\hline Gender & 1,959 & & 1,584 & \\
\hline Female & & $1,323(67.5)$ & & $1,076(67.9)$ \\
\hline Male & & $636 /(32.5)$ & & $508(32.1)$ \\
\hline Age (years) & 1,959 & & 1,584 & \\
\hline$<50$ & & $499(25.6)$ & & $342(21.6)$ \\
\hline $50-74$ & & $1,223(62.6)$ & & $1,016(64.1)$ \\
\hline$>74$ & & $231(11.8)$ & & $226(14.3)$ \\
\hline Household members & 1,953 & & 1584 & \\
\hline $1-3$ & & $1,106(56.6)$ & & $884(55.8)$ \\
\hline $4-6$ & & 709 (36.3) & & $588(37.1)$ \\
\hline $7-17$ & & $138(7.1)$ & & $112(7.1)$ \\
\hline Family monthly income & 1,940 & & 1,577 & \\
\hline$>$ US $\$ 327$ & & $1,037(53.1)$ & & $849(53.8)$ \\
\hline$\leq \mathrm{US} \$ 327$ & & $916(46.9)$ & & $728(46.1)$ \\
\hline Skin color & 1,950 & & 1578 & \\
\hline Mixed & & $1,144(58.6)$ & & $928(58.8)$ \\
\hline White & & $426(21.8)$ & & $339(21.5)$ \\
\hline Black & & $348(17.8)$ & & $282(17.9)$ \\
\hline Others & & $32(1.8)$ & & $29(0.2)$ \\
\hline Years of schooling & 1,950 & & 1,579 & \\
\hline Illiterate & & $670(34.4)$ & & $521(33.0)$ \\
\hline 1 to 4 & & $862(44.2)$ & & $732(46.4)$ \\
\hline 5 to 8 & & $320(16.4)$ & & $242(15.3)$ \\
\hline Other & & $98(5.0)$ & & $84(5.3)$ \\
\hline Marital status & 1,953 & & 1,580 & \\
\hline Married or living with partner & & $1,238(63.4)$ & & $1,022(64.7)$ \\
\hline Widower & & $449(23.0)$ & & $342(21.6)$ \\
\hline Single & & $176(9.0)$ & & $143(9.0)$ \\
\hline Divorced & & $90(4.6)$ & & $73(4.7)$ \\
\hline Health satisfaction & 1,076 & & 480 & \\
\hline Not at all satisfied & & $231(21.4)$ & & $126(20.7)$ \\
\hline Partially satisfied & & $232(21.6)$ & & $181(29.6)$ \\
\hline Very satisfied & & $613(57.0)$ & & $302(49.7)$ \\
\hline Health service used & Not collected & - & 1,558 & - \\
\hline Public & & - & & $1,043(66.9)$ \\
\hline Private & & - & & $354(22.7)$ \\
\hline Health Insurance & & - & & $18(1.2)$ \\
\hline None & & - & & $143(9.2)$ \\
\hline
\end{tabular}

Others in skin colors include Asian $(n=27)$ and Native Americans $(n=5)$; others in the educational level included: elementary school $(n=81)$ and graduate school $(n=17)$; Dollar conversion is from July 2013 (US\$1.00 $=R \$ 2.23$ ).

"inability to climb two flights of stairs" (38.9\%vs $63.1 \%)$, "pain when swallowing food" (17.8\% vs 30.8\%) and megaesophagus $(6.1 \%$ vs $11.4 \%)$.

In order to compare the variation between visits, we only selected patients who participated in both visits (Table 5). Use of ACE inhibitors and amiodarone reduced significantly (22.2\%vs $14.3 \%)$, and the use of ARBs (26.8\% vs 33.4\%) and aspirin $(25.1 \%$ vs $29.5 \%)$ increased. Most signs and symptoms reduced significantly except for night-time dyspnea, pedal edema in the morning and those related to megaesophagus. Twenty-seven (1.2\%) participants received a new pacemaker.

\section{DISCUSSION}

SaMi-Trop is one of the largest multi-center cohort studies of $\mathrm{ChD}$ disease in the world, and has led to a number of important scientific contributions to the understanding 
Table 3 - Clinical variables, health literacy and quality of life in the SAMI-TROP cohort at baseline and at the 2-years follow-up visit.

\begin{tabular}{|c|c|c|c|c|}
\hline \multirow{2}{*}{ Variables } & \multicolumn{2}{|c|}{ Baseline } & \multicolumn{2}{|c|}{ Follow-up 1} \\
\hline & Valid N & $\mathrm{N}(\%)$ & Valid $\mathrm{N}$ & $\mathrm{N}(\%)$ \\
\hline Previous use of benznidazole & 1,955 & & 1,581 & \\
\hline No & & $1,320(67.5)$ & & $1,055(66.7)$ \\
\hline Yes & & $492(25.2)$ & & $420(26.6)$ \\
\hline Do not know & & $143(7.3)$ & & $106(6.7)$ \\
\hline NYHA functional classification & 1,931 & & 1,560 & \\
\hline I & & $1,059(54.8)$ & & $895(56.5)$ \\
\hline II or more & & $872(45,2)$ & & $689(47.5)$ \\
\hline ProBNP level & 1,955 & & 1,518 & \\
\hline$<300 \mathrm{pg} / \mathrm{mL}$ & & $1,368(70.2)$ & & $1,068(69.2)$ \\
\hline$\geq 300$ & & $581(29.8)$ & & $474(30.8)$ \\
\hline ECG result & 1,910 & & 1,487 & \\
\hline Minor & & $326(17.1)$ & & $291(19.0)$ \\
\hline Normal & & $473(24.8)$ & & $315(21.1)$ \\
\hline Major & & $1,111(58.2)$ & & $905(59.9)$ \\
\hline Echocardiographic findings (median/IQ) & Not collected & & 1,564 & \\
\hline LV end-diastolic diameter (mm) & & & & $48(45-52)$ \\
\hline LV end-systolic diameter (mm) & & & & $31(29-36)$ \\
\hline LV ejection fraction (\%) & & & & $63(57-66)$ \\
\hline \multicolumn{5}{|l|}{ LV systolic dysfunction } \\
\hline No & & & & $1,357(87)$ \\
\hline Yes & & & & $203(13)$ \\
\hline Health literacy- SAHLPA & Not collected & - & 1,557 & \\
\hline Illiterate & & - & & $1,159(74)$ \\
\hline Inadequate health literacy & & - & & $339(21.8)$ \\
\hline Adequate health literacy & & - & & $59(3.84)$ \\
\hline Quality of life domains & 625 & Mean (SD) & 609 & Mean (SD) \\
\hline Physical & & $57.84(15.32)$ & & $60.7(17.6)$ \\
\hline Psychological & & $65.98(12.85)$ & & $65.4(15.5)$ \\
\hline Social relationships & & $73.17(13.99)$ & & $72.9(16.1)$ \\
\hline Environment & & $57.66(12.26)$ & & $59.8(14.6)$ \\
\hline
\end{tabular}

of $\mathrm{ChD}$ in endemic and remote areas ${ }^{13,15,20,23-28}$. Our results suggest that participation in SaMi-Trop improved the medical care of the participants. Specifically, the access to laboratory tests was improved and participants were re-evaluated by a cardiologist and underwent an ECHO assessment. This allowed for the diagnosis of both, $\mathrm{ChD}$ and the general health status. Furthermore, the SaMi-Trop project team conducted many meetings in the municipalities that participated in the study, with health professionals and government officials. The project has also raised the profile of the Telehealth system and provided training for physicians. One of the aspects of the project is the ethical commitment to patients: patients with more severe disease were scheduled for consultation with a physician or specialist for evaluation at a primary health care unit and received further care. All patients received information regarding $\mathrm{ChD}$ and self-care strategies. According to our results, the demographic profile is similar to the one of participants from other studies conducted in other regions ${ }^{29-31}$. Around $50 \%$ of our participants were classified as class 1 according to the NYHA functional classification, which means they have no significant symptoms. In the general population, the left ventricular function was preserved with a median for the ejection fraction of $63 \%$. Only $13 \%$ presented LV systolic dysfunction characterized by an ejection fraction of less than $50 \%$.

The study brings new information regarding how patients use health services and how they are able to understand health information and advice. The proportion of patients who reported the use of a private health service was high $(22.7 \%)$, compared to the general population in Brazil $^{32}$. Considering the lower level of family income, around $53 \%$ receive less than US\$400 per month, but this information requires further attention and will be discussed with the local health planners to better understand the underlying reasons. Another important observation was that almost $100 \%$ of the participants were considered not able to understand simple information regarding their health. Using a standardized questionnaire to evaluate the health literacy 
Table 4 - Comorbidities, selected behavioral characteristics, use of medication, signs and symptoms in the SaMi-Trop cohort at baseline and at the 2-years follow-up visit.

\begin{tabular}{|c|c|c|c|c|}
\hline \multirow{2}{*}{ Variables } & \multicolumn{2}{|c|}{ Baseline } & \multicolumn{2}{|c|}{ Follow-up 1} \\
\hline & Valid N & $\mathrm{N}(\%)$ & Valid N & $\mathrm{N}(\%)$ \\
\hline Comorbidities & 1,959 & & 1,558 & \\
\hline High serum cholesterol & & $785(40.1)$ & & $447(28.7)$ \\
\hline Hypertension & & $706(36.0)$ & & $1,016(65.2)$ \\
\hline Diabetes mellitus & & $198(10.1)$ & & $180(11.5)$ \\
\hline Thyroid disorder & & $159(8.1)$ & & $160(10.3)$ \\
\hline Kidney disease & & $143(7.3)$ & & $161(10.4)$ \\
\hline Leishmaniosis & & $22(1.2)$ & & $5(0.3)$ \\
\hline Behavioral characteristics & 1,945 & & 1,558 & \\
\hline Physical activity last week (30 min) & & $434(22.3)$ & & $365(23.4)$ \\
\hline Alcohol last month & & $318(16.2)$ & & $191(12.2)$ \\
\hline Current smoking & & $143(7.3)$ & & $91(5.8)$ \\
\hline Number of medications in use & 1,959 & & 1,528 & \\
\hline 0 & & $589(30.1)$ & & $367(23.5)$ \\
\hline $1-2$ & & $714(36.4)$ & & $601(38.6)$ \\
\hline $3-4$ & & $53827.5)$ & & $420(26.9)$ \\
\hline$\geq 5$ & & $1186.0)$ & & $140(8.9)$ \\
\hline Use of medication (Yes) & 1,940 & & 1,528 & \\
\hline Diuretics & & $951(49.1)$ & & $715(45.9)$ \\
\hline Angiotensin converting enzyme- ACE & & $553(28.6)$ & & $363(23.3)$ \\
\hline Angiotensin receptor blockers-ARBs & & $550(28.4)$ & & 519 (33.3) \\
\hline Aspirin & & $507(26.2)$ & & $460(29.5)$ \\
\hline Amiodarone & & $429(22.0)$ & & $209(13.4)$ \\
\hline Carvedilol & & $380(19.6)$ & & $297(19.0)$ \\
\hline Digoxin & & $140(7.2)$ & & $80(5.1)$ \\
\hline$\beta$-blockers & & $140(7.2)$ & & $112(7.2)$ \\
\hline Vasodilators (hydralazine) & & $84(4.3)$ & & $60(3.8)$ \\
\hline Warfarin & & $11(0.6)$ & & $8(0.5)$ \\
\hline Self-reported signs and symptoms (Yes) & 1,950 & & 1,558 & \\
\hline Heartbeat racing or beating abnormally & & $1,222(63.5)$ & & $854(54.8)$ \\
\hline Prolonged faintness or dizziness & & $429(21.9)$ & & $178(11.4)$ \\
\hline Problems on electrocardiogram & & $1,180(61.3)$ & & $829(53.2)$ \\
\hline Heart palpitations & & $1,174(61.0)$ & & $903(57.9)$ \\
\hline Shortness of breathe during physical exercises & & $1,143(59.4)$ & & $952(61.1)$ \\
\hline Heartbeat racing at rest & & $1,015(52.8)$ & & $615(39.5)$ \\
\hline Irregular heartbeat & & $902(46.9)$ & & 597 (38.3) \\
\hline Difficulty breathing when lying down & & $752(39.1)$ & & $662(42.5)$ \\
\hline Unable to climb two flights of stairs & & $749(38.9)$ & & $983(63.1)$ \\
\hline Awake during the night unable to breathe & & $683(35.5)$ & & $600(38.5)$ \\
\hline Trouble swallowing & & $599(31.1)$ & & $480(30.8)$ \\
\hline Swelling or puffiness of the feet (morning) & & $502(26.1)$ & & $457(29.3)$ \\
\hline No bowel movement for three or more days & & $478(24.8)$ & & $401(25.7)$ \\
\hline Visible neck veins (standing up or sitting) & & 409 21.3) & & $346(22.2)$ \\
\hline Pain when swallowing food & & $342(17.8)$ & & $480(30.8)$ \\
\hline Pacemaker & & $110(6.2)$ & & $112(7.2)$ \\
\hline Megaesophagus & & $117(6.1)$ & & $177(11.4)$ \\
\hline
\end{tabular}

helped to correct the underestimation of the education level self-reported by the patients. It is well known that inadequate health literacy can be a barrier to self-reported and treatment of diseases, therefore health professionals must adopt strategies to minimize these effects that can be harmful to the health due to inadequate literacy ${ }^{33,34}$.

In our cohort, those patients who died presented a higher proportion of comorbidities, more use of amiodarone, 
Table 5 - Statistical comparison of medications, signs and symptoms in the SaMi-Trop cohort for paired patients that participated in both visits. $\mathrm{N}=1,560$.

\begin{tabular}{|c|c|c|c|}
\hline \multirow{2}{*}{ Variables } & \multirow{2}{*}{$\begin{array}{c}\text { Baseline } \\
\mathrm{N}(\%) \\
\end{array}$} & \multirow{2}{*}{$\begin{array}{c}\text { Follow-up } 1 \\
\mathrm{~N}(\%) \\
\end{array}$} & \multirow{2}{*}{ P-value } \\
\hline & & & \\
\hline \multicolumn{4}{|c|}{ Medication in use (Yes) } \\
\hline \multicolumn{4}{|c|}{$\operatorname{ACE}^{a}(n=1,512)$} \\
\hline No & $1,081(71.5)$ & $1,155(76.4)$ & \\
\hline Yes & $431(28.5)$ & $357(23.6)$ & 0.000 \\
\hline \multicolumn{4}{|c|}{$\operatorname{ARBs}^{b}(n=1,513)$} \\
\hline No & $1,107(73.2)$ & $1,008(66.6)$ & \\
\hline Yes & $406(26.8)$ & $505(33.4)$ & 0.000 \\
\hline \multicolumn{4}{|c|}{ Aspirin $(n=1,513)$} \\
\hline No & $1,104(74.9)$ & $1,067(70.5)$ & \\
\hline Yes & $379(25.1)$ & $446(29.5)$ & 0.003 \\
\hline \multicolumn{4}{|c|}{ Amiodarone $(n=1,368)$} \\
\hline No & $1,064(77.8)$ & $1,172(85.7)$ & \\
\hline Yes & $304(22.2)$ & $196(14.3)$ & 0.000 \\
\hline \multicolumn{4}{|c|}{ Self-reported signs and symptoms (Yes) } \\
\hline \multicolumn{4}{|c|}{ Heartbeat racing or beating abnormally $(n=1,501)$} \\
\hline No & $546(36.4)$ & $680(45.3)$ & \\
\hline Yes & $955(63.6)$ & $821(54.7)$ & 0.000 \\
\hline \multicolumn{4}{|c|}{ Prolonged faintness or dizziness $(n=1,513)$} \\
\hline No & $1,182(78.1)$ & $1,339(88.5)$ & \\
\hline Yes & $331(21.9)$ & $174(11.5)$ & 0.000 \\
\hline \multicolumn{4}{|c|}{ Problems on electrocardiogram $(n=1,527)$} \\
\hline No & $602(39)$ & $730(47.8)$ & \\
\hline Yes & $925(61)$ & $797(52.2)$ & 0.000 \\
\hline \multicolumn{4}{|c|}{ Heartbeat racing at rest $(n=1,501)$} \\
\hline No & $711(47.4)$ & $908(60.5)$ & \\
\hline Yes & $790(52.6)$ & $593(39.5)$ & 0.000 \\
\hline \multicolumn{4}{|c|}{ Irregular heartbeat $(n=1,501)$} \\
\hline No & $808(53.8)$ & $929(61.9)$ & \\
\hline Yes & $693(46.2)$ & $572(38.1)$ & 0.000 \\
\hline \multicolumn{4}{|c|}{ Awake during the night unable to breathe $(n=1,501)$} \\
\hline No & $982(65.4)$ & $923(61.5)$ & \\
\hline Yes & $519(34.6)$ & $578(38.5)$ & 0.008 \\
\hline \multicolumn{4}{|c|}{ Swelling or puffiness of the feet (morning) $(n=1,501)$} \\
\hline No & $1,116(74.3)$ & $1,059(70.5)$ & \\
\hline Yes & $385(25.7)$ & $442(29.5)$ & 0.005 \\
\hline \multicolumn{4}{|c|}{ Pacemaker $(\mathrm{n}=1,501)$} \\
\hline No & $1,420(94.7)$ & $1,393(92.8)$ & \\
\hline Yes & $81(5.3)$ & $108(7.2)$ & 0.000 \\
\hline \multicolumn{4}{|c|}{ Megaoesophagus $(n=1,501)$} \\
\hline No & $1,414(94.2)$ & $1,328(88.5)$ & \\
\hline Yes & $87(5.8)$ & $173(11.5)$ & 0.000 \\
\hline
\end{tabular}

${ }^{*}$ Test the equality of matched pairs (Wilcoxon matched-pairs test); ${ }^{\mathrm{A} A C E}=$ Angiotensin converting enzyme; ${ }^{\mathrm{b}} \mathrm{ARBs}=\mathrm{Angiotensin}$ receptor blockers.

functional class II or higher classification, and more pacemakers. This was expected because these patients were likely to have more severe disease. Among those patients who participated in both visits (baseline and follow-up 1), we found that many of them had reduced the use of amiodarone. One possible explanation is that they were examined by a cardiologist and the prescribed medication was probably reviewed. Another possible explanation is that the side effects of the medicine have motivated the patients to discontinue the medication. Stein et al..$^{35}$ found that patients taking amiodarone presented side effects which vary from $10.6 \%$ to $61.1 \%$, and $7.68 \%$ discontinued the 
drug. We observed that $27.2 \%$ of the patients reported a previous use of benznidazole, but the use was more frequent among individuals with better demographic conditions and a longer time since the $\mathrm{CD}$ diagnosis ${ }^{23}$. The use of benznidazole was beneficial to reduce the parasitemia and the mortality rate according to our results ${ }^{15}$. In another cohort study, treatment with benznidazole was associated with a decrease in $\mathrm{ChD}$ progression from the indeterminate form to the cardiac one and also a decrease in the risk of cardiovascular events ${ }^{36}$.

A limitation out of our study was the number of participants lost to follow-up; $13 \%$ of subjects did not participate in the FU1 visit. We believe this was due to the high degree of disease severity of the participants and the challenges of working in a remote region of Minas Gerais State. Another limitation is that the ECHO results are available only for the first follow-up visit so that some comparisons were not possible. However, the ECHOs will be repeated for all the participants in the second follow-up visit.

\section{CONCLUSION}

In conclusion, our results confirmed that abnormal NT-proBNP level adjusted by age as a strong predictor of death ${ }^{13}$, which reinforces that benznidazole should be strongly considered in the treatment of chronic $\mathrm{ChD}$, and the quality of life is worse in these patients. Additionally, we detected, as expected, a greater use of some medicines such as ARBs and aspirin and a higher mortality rate among those who have more severe disease. The SaMi-Trop project has also started its second visit (follow-up 2), before its interruption due the COVID-19 pandemic, and its contribution to fill some gaps in the knowledge regarding $\mathrm{ChD}$ progression is very important.

Some positive findings in our study need to be highlighted, such as the fact that the project enabled the training of human resources, gave technical support for the local primary health care in order to improve the medical care provided to the patients, and should improve medical assistance as well as the management of treatment which will probably contribute to improve the quality of life of the patients. These findings reinforce the importance of adequate financial support from governments to help Chagas patients to have access to healthcare.

\section{ACKNOWLEDGMENTS}

The SaMi-Trop project has many collaborations with others research institutes. We would like to acknowledge the collaboration with the Institut MeArieux (France) and the Vitalant Research Institute (US).

\section{AUTHORS' CONTRIBUTIONS}

CDLO, CCS, ALPR and ECS were responsible for study concept, analyzed and interpreted the data, drafted and revised the manuscript, and approved the final version. LCO, LN, NDQ, AMF, ECN, ALB, LB, DSH and ALR have substantially contributed to the drafting of the article or revising it critically for important intellectual content; and have given the final approval of the version to be published.

\section{FUNDING}

The SaMi-Trop cohort study is supported by the National Institutes of Health (NIH), (P50 AI098461-02), Brazilian National Research Council, CNPq (467043/2014-0) and the State Funding Agency of Minas Gerais, FAPEMIG (REDE 018-14). ALPR is supported in part by CNPq (310679/20168 and 465518/2014-1), by FAPEMIG (PPM-00428-17 and RED-00081-16).

\section{REFERENCES}

1. Nunes MC, Beaton A, Acquatella H, Bern C, Bolger AF, Echeverría LE, et al. Chagas cardiomyopathy: an update of current clinical knowledge and management: a scientific statement From the American Heart Association. Circulation. 2018;138:e169-209.

2. Bonney KM. Chagas disease in the 21 st century: a public health success or an emerging threat? Parasite. 2014;21:11.

3. Gascon J, Bern C, Pinazo MJ. Chagas disease in Spain, the United States and other non-endemic countries. Acta Trop. 2010;115:22-7.

4. Echeverría LE, Marcus R, Novick G, Sosa-Estani S, Ralston K, Zaidel EJ, et al. WHF IASC Roadmap on Chagas Disease. Glob Heart. 2020;15:26.

5. Baldoni NR, Quintino ND, Alves GC, Oliveira CD, Sabino EC, Ribeiro AL, et al. Quality of life in patients with Chagas disease and the instrument used: an integrative review. Rev Inst Med Trop Sao Paulo. 2021;63:e46.

6. Martins-Melo FR, Ramos Jr AN, Alencar CH, Lange W, Heukelbach J. Mortality of Chagas' disease in Brazil: spatial patterns and definition of high-risk areas. Trop Med Int Health. 2012;17:1066-75.

7. Lima MM, Costa VM, Palmeira SL, Castro AP. Estratificação de territórios prioritários para vigilância da doença de Chagas crônica: análise multicritério para tomada de decisão em saúde. Cad Saude Publica. 2021;37:e0175920.

8. Issa VS, Ayub-Ferreira SM, Schroyens M, Chizzola PR, Soares $\mathrm{PR}$, Lage $\mathrm{SH}$, et al. The course of patients with Chagas heart disease during episodes of decompensated heart failure. ESC Heart Fail. 2021;8:1460-71. 
9. Hasslocher-Moreno AM, Xavier SS, Saraiva RM, Sangenis LH, Holanda MT, Veloso HH, et al. Progression rate from the indeterminate form to the cardiac form in patients with chronic Chagas disease: twenty-two-year follow-up in a Brazilian urban cohort. Trop Med Infect Dis. 2020;5:76.

10. Silva CP, Del Carlo CH, Oliveira Junior MT, Scipioni A, StrunzCassaro C, Ramirez JA, et al. Why do patients with chagasic cardiomyopathy have worse outcomes than those with nonchagasic cardiomyopathy? Arq Bras Cardiol. 2008;91:358-62.

11. Borges-Pereira J, Coura JR, Zauza PL, Pirmez C, Xavier SS. Chagas disease in Virgem da Lapa, Minas Gerais, Brazil: left ventricle aneurysm and the risk of death in the 24-year interval. Mem Inst Oswaldo Cruz. 2020;115:e200056.

12. Cardoso CS, Sabino EC, Oliveira CL, Oliveira LD, Ferreira AM, Cunha-Neto E, et al. Longitudinal study of patients with chronic Chagas cardiomyopathy in Brazil (SaMi-Trop project): a cohort profile. BMJ Open. 2016;6:e011181.

13. Oliveira CD, Nunes MC, Colosimo EA, Lima EM, Cardoso CS, Ferreira AM, et al. Risk score for predicting 2-year mortality in patients with Chagas cardiomyopathy from endemic areas: SaMi-Trop Cohort Study. J Am Heart Assoc. 2020;9:e014176.

14. Ferreira AM, Sabino EC, Oliveira LC, Oliveira CD, Cardoso CS, Ribeiro AL, et al. Impact of the social context on the prognosis of Chagas disease patients: Multilevel analysis of a Brazilian cohort. PLoS Negl Trop Dis. 2020;14:e0008399.

15. Cardoso CS, Ribeiro AL, Oliveira CD, Oliveira LC, Ferreira AM, Bierrenbach AL, et al. Beneficial effects of benznidazole in Chagas disease: NIH SaMi-Trop cohort study. PLoS Negl Trop Dis. 2018;12:e006814.

16. Alkmim MB, Figueira RM, Marcolino MS, Cardoso CS, Pena de Abreu M, Cunha LR, et al. Improving patient access to specialized health care: the Telehealth Network of Minas Gerais, Brazil. Bull World Health Organ. 2012;90:373-8.

17. Ribeiro AH, Ribeiro MH, Paixão GM, Oliveira DM, Gomes PR, Canazart JA, et al. Automatic diagnosis of the 12-lead ECG using a deep neural network. Nat Commun. 2020;11:1760.

18. Lopes EL, Beaton AZ, Nascimento BR, Tompsett A, Santos JP, Perlman L, et al. Telehealth solutions to enable global collaboration in rheumatic heart disease screening. J Telemed Telecare. 2018;24:101-9.

19. Silva M, Palhares D, Ribeiro L, Gomes P, Macfarlane P, Ribeiro A, et al. Prevalence of major and minor electrocardiographic abnormalities in one million primary care Latinos. J Electrocardiol. 2020;64:36-41.

20. Quintino ND, Sabino EC, Silva JL, Ribeiro AL, Ferreira AM, Davi GL, et al. Factors associated with quality of life in patients with Chagas disease: SaMi-Trop project. PLoS Negl Trop Dis. 2020;14:e0008144.

21. Capuani L, Bierrenbach AL, Alencar AP, Mendrone Jr A, Ferreira JE, Custer B, et al. Mortality among blood donors seropositive and seronegative for Chagas disease (1996-2000) in São Paulo,
Brazil: a death certificate linkage study. PLoS Negl Trop Dis. 2017;11:e0005542.

22. Apolinario D, Braga RC, Magaldi RM, Busse AL, Campora F, Brucki S, et al. Short assessment of health literacy for Portuguese-speaking adults. Rev Saude Publica. 2012;46:70211.

23. Ferreira AM, Sabino EC, Oliveira LC, Oliveira CD, Cardoso CS, Ribeiro AL, et al. Benznidazole use among patients with chronic Chagas' cardiomyopathy in an endemic region of Brazil. PLoS One. 2016;11:e0165950.

24. Zrein M, Granjon E, Gueyffier L, Caillaudeau J, Liehl P, Pottel H, et al. A novel antibody surrogate biomarker to monitor parasite persistence in Trypanosoma cruzi-infected patients. PLoS Negl Trop Dis. 2018;12:e006226.

25. Brito BO, Pinto-Filho MM, Cardoso CS, Oliveira CD, Ferreira AM, Oliveira LC, et al. Association between typical electrocardiographic abnormalities and NT-proBNP elevation in a large cohort of patients with Chagas disease from endemic area. J Electrocardiol. 2018;51:1039-43.

26. Oliveira LC, Pereira NB, Moreira CH, Bierrenbach AL, Salles FC, Souza-Basqueira M, et al. ELISA saliva for Trypanosoma cruzi antibody detection: an alternative for serological surveys in endemic regions. Am J Trop Med Hyg. 2020;102:800-3.

27. Oliveira LC, Lee TH, Ferreira AM, Bierrenbach AL, SouzaBasqueira M, Oliveira CD, et al. Lack of evidence of seronegative infection in an endemic area of Chagas disease. Rev Inst Med Trop Sao Paulo. 2019;61:e11.

28. Damasceno RF, Sabino EC, Ferreira AM, Ribeiro AL, Moreira HF, Prates TE, et al. Challenges in the care of patients with Chagas disease in the Brazilian public health system: A qualitative study with primary health care doctors. PLoS Negl Trop Dis. 2020;14:e0008782.

29. Gontijo ED, Rocha MO, Torquato de Oliveira U. Perfil clínicoepidemiológico de chagásicos atendidos em ambulatório de referência e proposição de modelo de atenção ao chagásico na perspectiva do SUS. Rev Soc Bras Med Trop. 1996;29: 101-8.

30. Pereira LS, Freitas EC, Fidalgo AS, Andrade MC, Cândido DS, Silva Filho JD, et al. Clinical and epidemiological profile of elderly patients with Chagas disease followed between 2005-2013 by pharmaceutical care service in Ceará State, Northeastern Brazil. Rev Inst Med Trop Sao Paulo. 2015;57:145-52.

31. Hasslocher-Moreno AM, Saraiva RM, Brasil PE, Sangenis LH, Xavier SS, Sousa AS, et al. Temporal changes in the clinical-epidemiological profile of patients with Chagas disease at a referral center in Brazil. Rev Soc Bras Med Trop. 2021;54:e00402021.

32. Atun R, Andrade LO, Almeida G, Cotlear D, Dmytraczenko T, Frenz P, et al. Health-system reform and universal health coverage in Latin America. Lancet. 2015;385:1230-47. 
33. Cajita MI, Cajita TR, Han HR. Health literacy and heart failure: a systematic review. J Cardiovasc Nurs. 2016;31:121-30.

34. Oscalices MI, Okuno MF, Lopes MC, Batista RE, Campanharo CR. Health literacy and adherence to treatment of patients with heart failure. Rev Esc Enferm USP. 2019;53:e03447.

35. Stein C, Migliavaca CB, Colpani V, Rosa PR, Sganzerla D, Giordani NE, et al. Amiodarone for arrhythmia in patients with
Chagas disease: a systematic review and individual patient data meta-analysis. PLoS Negl Trop Dis. 2018;12:e0006742.

36. Hasslocher-Moreno AM, Saraiva RM, Sangenis LH, Xavier SS, Sousa AS, Costa AR, et al. Benznidazole decreases the risk of chronic Chagas disease progression and cardiovascular events: a long-term follow up study. EClinicalMedicine. 2021;31:100694. 